\title{
A STUDY OF STRESS AND AUTONOMIC FUNCTION TEST IN MEDICAL STUDENTS
}

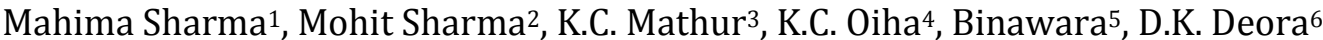

\section{HOW TO CITE THIS ARTICLE:}

Mahima Sharma, Mohit Sharma, K.C. Mathur, K.C. Oiha, Binawara, D.K. Deora. "A Study of Stress and Autonomic Function Test in Medical Students". Journal of Evolution of Medical and Dental Sciences 2014; Vol. 3, Issue 07, February 17; Page: 1672-1680, DOI: 10.14260/jemds/2014/2041

ABSTRACT: BACKGROUND: Medical students are frequently described as stressed in comparison with general population. ${ }^{1,2}$ Particularly examinations are a major cause of stress. ${ }^{3}$ High level of stress may have adverse effect on academic achievement. However there is a deficit of information regarding the interrelationship of stress and academic performance in medical students. The present study adds to the literature of the level of stress during examination and its impact on performance in a cohort of first year medical students. The study also discusses the areas where medical students are more stressful, effects of stress, student's adaptation styles, and intervention measures to deal with stress, as it is believed that healthy medical students are likely to become healthy doctors who can then be model and promote healthy lifestyles with their patients. ${ }^{4}$

\section{AIMS AND OBJECTIVES:}

1. To determine the effect of stress measured by self-evaluation questionnaire.

2. Impact of examination stress on the academic performance of first year medical students.

3. To study effect of premenstrual stress on autonomic function.

MATERIAL AND METHODS: A prospective cohort study was conducted on medical students to determine the examination stress measured by anxiety questionnaire and autonomic function tests. One hundred medical students studying in first academic year admitted for the first year during 2011-2012 in S.P. Medical College, Bikaner. Stress was measured during first terminal examination since it was the first major examination faced by the students after entering into the professional course.

SUMMARY AND CONCLUSION: In consort with previous research, the examination of first year medical students is stressful enough to affect the performance adversely. Since stress around examinations is strongly predicting the academic achievement, students should be exposed to stress management techniques to help prevent the known high consequences.

INTRODUCTION: Medical education is long and at some instances tiring. The student often realizes about his/her future/career. When his fellow colleagues have started their career, got married, got issues, developed bank balance and so on - so forth, he has just not started even. This creates many times stress among medical students. This also explains the fact that at present time sections of science biology at school level are lying vacant.

The students are coming from school standard (after $12^{\text {th }}$ class) and more than $90 \%$ are from Hindi medium. They are unable to understand English language teaching in medical institutions and in such atmosphere when they know that they have to face an examination here, they go under stress. 


\section{ORIGINAL ARTICLE}

STRESS AND ITS EFFECTS ON MEDICAL STUDENTS: Negative consequences of stress identified by many studies show in areas of academics, learning interpersonal relationships psychological functioning and physical health.5, 6

Stress in medical students is associated with poor performance and emotional distress in first year medical students may lead to serious social consequences in subsequent years. ${ }^{7,8}$ Stress is also known to decrease memory functions, attention and cognitive functions. ${ }^{9}$ Stress is associated with other psychiatric symptoms such as depression. ${ }^{10}$

Stress effects on immune system have been described by lot of studies in medical students. It changes blood cell parameters and cell mediated immune response ${ }^{11,12}$. Antibody, certain cytokines are reported as being suppressed during high stress making them prone for viral infections, cold, allergies/asthmatic and autoimmunity diseases. ${ }^{13}$

STUDY DESIGN: A prospective cohort study was conducted on medical students to determine the examination stress measured by anxiety questionnaire and autonomic function tests.

STUDY POPULATION: One hundred medical students studying in first academic year admitted for the first year during 2011-2012 in S.P. Medical College, Bikaner.

SAMPLE SIZE: The total strength of $1^{\text {st }}$ year medical students was 150 . Using a random number table, 100 were selected. Additional 20 students who wanted to participate in the study were also enrolled. To study effect of premenstrual stress on autonomic function, 20 girls were included in study.

Thus systematic randomly selected cohort of $1^{\text {st }}$ year medical students was the sample for the study underwent evaluation at three intervals as follows:

1. Midterm Pre - examination.

2. During the first terminal examination - interval between essay paper and practical examination.

3. One month after the first terminal examination - Post examination.

INCLUSION CRITERIA: All healthy $1^{\text {st }}$ year medical students who were mentally and physically fit, studying in the $1^{\text {st }}$ academic term were included in the study.

EXCLUSION CRITERIA: Students with any illness fever or on drug treatment were excluded from the study.

METHOD: A written informed consent was obtained from the participants. Information about demographic, social, cultural and lifestyle factors were collected using a proforma of questionnaire. Name, age, sex and nativity were also recorded. Stress was measured during first terminal examination since it was the first major examination faced by the students after entering into the professional course. Three parameters were used to measure the level of stress.

1. Spielberger state trait anxiety inventory (STAI) self-evaluation questionnaire to measure the level of stress.

2. Premenstrual stress questionnaire ${ }^{78}$ was used to evaluate the symptoms of premenstrual stress.

3. Autonomic function tests 
STAI SELF EVALUATION QUESTIONNAIRE: Spielberger state trait anxiety inventory (STAI) selfevaluation questionnaire was used to measure the level of stress. The STAI inventory comprises of separate self-report scales for measuring two distinct anxiety concepts: anxiety state (Astate) and anxiety trait (A trait). "State" items ask the respondent to indicate how he/she generally feels. Each section of the inventory comprises of 20 items.

ADMINISTRATION OF QUESTIONNAIRS: The participant has no time limit for responding to the questionnaire. However, students generally require only six to eight minutes to complete either section and less than fifteen minutes to complete both.

SCORING: Participants respond to each STAI item by rating themselves on a four point scale. Hence the range of possible scores varies from a minimum of 20 to a maximum of 80 on both the A state and A trait subscales.

The students were subdivided into two groups based on STAI state anxiety scores with those scoring $<40$ considered as low anxiety group while those with a score of $>40$ were considered as high anxiety group.

\section{AUTONOMIC FUNCTION TEST:}

Autonomic function tests will be carried out using

1. Electrocardiograph

2. sphygmomanometer

\section{PROCEDURE OF AUTONOMIC FUNCTION TEST EVALUATION:}

1. DEEP BREATHING TEST: In the sitting position subject was asked to breathe quietly and deeply at the rate of 6 breaths per minutes. A continues ECG was recorded for six cycles, with marker to indicate the onset of each inspirator and expiration R-R interval were measured during each breathing cycles and converted to beats per minutes. The result was then expressed as mean of the difference between maximum and minimum heart rate for six measured cycles in beats per minutes.

Deep Breathing Difference $(\mathrm{DBD})=$ mean of heart rate difference on 6 breath cycle. A normal response was a difference of 15 beat/min on, 11-14 beats/min borderline and less than 10 beat/minutes was considered abnormal.

2. HEART RATE VARIATION TO VALSALVA MANEUVER: The subject was seated comfortably and was asked to blow into a mouth piece attached to mercury sphygmomanometer and holding it at pressure of $40 \mathrm{mmHg}$ for 15 seconds while a continuous ECG was being recorded. The ECG was continued to be recorded after release of pressure at the end of 15 seconds for 30 seconds the heart rate changes induced by valsalva manoeuvre was expressed as the rates of the maximal tachycardia during the maneuver to the maximal bradycardia after the manoeuvre. This rate was defined as valsalva ratio and was calculated as ratio of maximum $\mathrm{R}-\mathrm{R}$ interval during the maneuver to minimum R-R interval after the maneuver.

$$
\begin{gathered}
\text { Valsalva ratio }(\mathrm{VR})=\text { Maximal tachycardia/maximum bracycardia } \\
=\text { maximum } \mathrm{R}-\mathrm{R} \text { interval/minimum } \mathrm{R}-\mathrm{R} \text { interval }
\end{gathered}
$$


A value of 1.10 or less is defined as an abnormal response, $1.11-1.20$ as borderline and 1.21 or more as a normal response.

3. HEART RATE RESPONSE TO STANDING-POSTURAL TACHYCARDIA INDEX (PTI): The subjects were asked to lie on the examination table quietly while heart rate is being recorded on ECG. They were then asked to stand up unaided and ECG was recorded for 1 min. The shortest R-R interval at on around $15^{\text {th }}$ beat and longest $\mathrm{R}-\mathrm{R}$ interval at or around $30^{\text {th }}$ beat was measured. The result was expressed as ratio of $30 / 15$.

$$
\text { PTI = } \begin{gathered}
\text { Longest R-R interval at } 30^{\text {th }} \text { beat } \\
\text { Shortest R-R interval at } 15^{\text {th }} \text { beat }
\end{gathered}
$$

A ratio of 1.00 or less was defined as an abnormal response, $1.01-1.03$ as borderline and 1.04 as normal response.

4. BP RESPONSE TO STANDING (ORTHOSTATIC TEST): The subject was asked to rest in a supine position for 5 minutes. The resting BP was recorded. The subject was then asked to stand unaided and remain standing unsupported for 3 minutes. The BP was recorded at 30 seconds and 3 minutes after standing up. The difference between the resting and stand by BP level was calculated. The fact of $30 \mathrm{mmHg}$ or more was defined as abnormal, fall between 11-29 $\mathrm{mmHg}$ as borderline and fall of $10 \mathrm{mmHg}$ or less was considered normal.

Heart rate response to deep breathing, valsalva maneuver and standing are known as tests to evaluate parasympathetic nervous system pathway, whereas BP response to standing allow the assessment of sympathetic nervous system activity.

OBSERVATIONS: Student's ' $t$ ' test was used for analysis of the data. Statistical results were considered significant at $\mathrm{p}<0.05$.

\begin{tabular}{|c|c|c|c|c|c|c|}
\hline \multirow{2}{*}{ STAI } & \multicolumn{2}{|c|}{ Pre-Examination } & \multicolumn{2}{|c|}{ During Examination } & \multicolumn{2}{c|}{ After Examination } \\
\cline { 2 - 7 } & Mean & SD & Mean & SD & Mean & SD \\
\hline State & 38.79 & 9.80 & 43.49 & 11.62 & 38.62 & 8.95 \\
\hline Trait & 43.59 & 9.52 & 43.23 & 9.79 & 40.88 & 9.01 \\
\hline \multicolumn{2}{|c|}{ Group Comparison } & \multicolumn{2}{|c|}{ t } & \multicolumn{2}{c|}{ p } \\
\hline STAI State Before Vs. During & \multicolumn{2}{|c|}{3.747} & \multicolumn{2}{c|}{$<0.001$} \\
\hline STAI State Before Vs. After & \multicolumn{2}{|c|}{0.155} & \multicolumn{2}{c|}{0.877} \\
\hline STAI State During Vs. After & \multicolumn{2}{|c|}{4.331} & \multicolumn{2}{c|}{0.001} \\
\hline STAI Trait Before Vs. During & \multicolumn{2}{|c|}{0.352} & \multicolumn{2}{c|}{0.011} \\
\hline STAI Trait Before Vs. After & \multicolumn{2}{|c|}{2.586} & \multicolumn{2}{|c|}{0.003} \\
\hline STAI Trait During Vs. After & \multicolumn{2}{|c|}{3.097} &
\end{tabular}

TABLE 1: Comparison of STAI state and trait anxiety scores on three intervals 


\begin{tabular}{|l|c|c|c|c|c|c|}
\hline \multirow{2}{*}{ AFT Sub groups } & \multicolumn{2}{|c|}{ Pre-Examination } & \multicolumn{2}{c|}{ During Examination } & \multicolumn{2}{c|}{ After Examination } \\
\cline { 2 - 7 } & No. & $\%$ & No. & $\%$ & No. & $\%$ \\
\hline Normal & 88 & 88 & 86 & 86 & 93 & 93 \\
\hline Abnormal & 12 & 12 & 14 & 14 & 7 & 7 \\
\hline
\end{tabular}

TABLE 2: Heart Rate Variation during deep breathing

\begin{tabular}{|l|c|c|c|c|c|c|}
\hline \multirow{2}{*}{ AFT Sub groups } & \multicolumn{2}{|c|}{ Pre-Examination } & \multicolumn{2}{c|}{ During Examination } & \multicolumn{2}{c|}{ After Examination } \\
\cline { 2 - 7 } & No. & $\%$ & No. & $\%$ & No. & $\%$ \\
\hline Normal & 84 & 84 & 89 & 89 & 90 & 90 \\
\hline Abnormal & 16 & 16 & 11 & 11 & 10 & 10 \\
\hline
\end{tabular}

TABLE 3: Heart Rate response to standing

\begin{tabular}{|l|c|c|c|c|c|c|}
\hline \multirow{2}{*}{ AFT Sub groups } & \multicolumn{2}{|c|}{ Pre-Examination } & \multicolumn{2}{c|}{ During Examination } & \multicolumn{2}{c|}{ After Examination } \\
\cline { 2 - 7 } & No. & $\%$ & No. & $\%$ & No. & $\%$ \\
\hline Normal & 89 & 89 & 75 & 75 & 70 & 70 \\
\hline Abnormal & 11 & 11 & 25 & 25 & 30 & 30 \\
\hline
\end{tabular}

TABLE 4: Heart Rate response to Valsalva Maneuver

\begin{tabular}{|c|c|c|c|c|c|c|}
\hline \multicolumn{2}{|c|}{ STAI } & \multicolumn{2}{|c|}{ Examination Score } & \multirow{2}{*}{ T } & \multirow{2}{*}{$\mathrm{p}$} \\
\cline { 3 - 6 } \multicolumn{2}{|c|}{} & Mean & SD & SE & & \\
\hline \multirow{2}{*}{ State } & $<40(n=62)$ & 55.56 & 4.67 & 0.59 & \multirow{2}{*}{3.371} & \multirow{2}{*}{0.001} \\
\cline { 2 - 5 } & $>40(n=38)$ & 51.97 & 5.87 & 0.95 & & \\
\hline \multirow{2}{*}{ Trait } & $<40(n=34)$ & 55.19 & 3.87 & 0.66 & \multirow{2}{*}{1.324} & \multirow{2}{*}{0.189} \\
\cline { 2 - 5 } & $>40(n=66)$ & 53.68 & 6.03 & 7.42 & & \\
\hline
\end{tabular}

TABLE 5: Comparison of STAI and Examination Score

DISCUSSION: Present study was conducted in the department of Physiology, S.P. Medical College, Bikaner on medical students on three intervals of one academic year; middle of the $1^{\text {st }}$ term (pre examination), interval between essay paper and practical examination and one month after the completion of the first terminal examination (post examination), to determine the effects of examination stress on academic performance.

Stress observed following a stressful stimulus depends on the nature of the stimulus. University examinations are a kind of summative examination, known to be associated with higher stress compared to the formative examinations conducted periodically. To measure the level of stress STAI anxiety scale was used, as many investigators have used it previously, and considered it as validated instrument. To test the neuronal activity autonomic function tests were chosen because they are reliable and noninvasive tests which can be carried out easily on the subjects. In the study it was noticed that anxiety scores were elevated from baseline to examination and significantly decreased during post examination period from examination. It was also observed that number of 
students with abnormal AFT increased during examination from baseline, but remained increased during post examination.

As there is increase in anxiety there is increase in cortisol level. These finding were similar to studies that describe stress in the form of continuous mental task elevates salivary cortisol significantly and stressed individual reacted with high cortisol 16. Another study found that examination period was associated with significant reduction in cortisol and reduction was associated with enhanced memory. It was also observed that number of students with abnormal AFT increased during examination from baseline, but remained increased during post examination. This is supported by many earlier studies which found elevated cortisol levels in the group with perceived high anxiety scores.

The group that responded with higher cortisol during examination showed better performance. This is supported by the study that found poorer mental health scores possibly associated with lower cortisol scores when salivary cortisol levels were considered. In the present study it was observed that higher the anxiety decreased the examination performance. The negative association between anxiety and performance was observed by the previous study, which noticed that high anxiety scores are likely to impair performance.

The results of this study should help understand the pattern of response to the examination stress and enable development of strategies that will assist the students to handle the stress in a more efficient manner. The strategies could be the one, which enable the students to face the examination or to increase the number of formative tests that will give feedback to the students and guide them to improve deficiencies in learning. In the menstrual stress it was observed that autonomic function test were found abnormal during premenstrual and postmenstrual phase significantly higher heart rate, systolic and diastolic blood pressure in basal condition changes in autonomic function may be responsible for some of the symptoms produced through endorphins and have been held responsible for behavioral changes.

Increased blood pressure due to premenstrual stress is due to increase in peripheral resistance and is mediated by adreno cortical stimulation causing precapillary resistance. This could be due to increased sympathetic activity or elevation of circulating catecholamine while other active hormone like rennin, angiotensin aldosterone also contribute, Rise in blood pressure due to stress leads to increased epinephrine secretion Rise in blood pressure is important sympatho-adrenal response to physiological stressful experience caused by premenstrual stress.

According to Tamki women with greater degree of premenstrual distress possess higher sympathetic activity in late luteal phase than women with fewer symptoms. Change in physiological response in premenstrual response in premenstrual syndrome group is because of increased sympathetic activity resulting from modulation of neurotransmitter due to hormonal fluctuation. Relaxation technique should be recommended as an adjuvant therapy to tilt the autonomic balance to parasympathetic dominance to get relieve from premenstrual symptoms.

The findings of the present study have implications for studies that evaluate the role of stress on psychology, endocrine system and impaired neuronal activity in humans. To confirm whatever pattern of response, which was observed, study needs to be evaluated on larger scale. Electroencephalography (E.E.G), nerve conduction studies and other cognitive ability tests could have been included in the study to assess the functional status of nervous system during stress. 
Further follow up of this cohort may have varied response to stress as the students are exposed to the examination stimulus many times and their modified learning abilities, may show reduced stress response or the students who are entering in to the clinical phase, have much more subjects to master may have heightened response. Continued follow up of the same cohort may be more informative in this regard.

SUMMARY AND CONCLUSIONS: This study was carried out to know the impact of examination stress on academic performance in first year medical students. After informed consent, using two parameters examination stress was measured at two intervals; at baseline, examination and postexamination period.

The study revealed that,

1. The group with elevated anxiety was associated with increased abnormal autonomic functions from baseline to examinations.

2. Anxiety levels decreased in post-examination period.

3. In contrast abnormal autonomic functions did not decrease during post examination period. All the three parameters were correlated linearly from baseline to examination.

4. The expected pattern of increased anxiety during examination and decreased anxiety scores in post examination was observed.

5. Examination performance is being affected adversely by increased stress level measured by the parameters mentioned above.

The results of this study should help understand the pattern of response to the examination stress and enable development of strategies that will assist the students to handle the stress in a more efficient manner.

Autonomic function test were conducted on twenty normal girls without any co-morbidity during premenstrual and post menstrual phase.

1. The result was not significant in case of heart rate variation during deep breathing, heart rate response to standing, heart rate response to Valsalva maneuver.

2. Highly significant in case of blood pressure response to standing.

It is possible that there is an alteration in autonomic nervous system activity in the normal menstrual cycle with predominant sympathetic nervous system activity in the luteal phase. These observed changes in the cardiovascular parameters can be attributed to the established actions of ovarian steroids predominant during these phases i.e. follicular phase, estrogen and luteal phase progesterone.

Inspite of the limitation in being a non-invasive technique the present study provides data that should be clinically useful to the gynecologist in making a diagnosis of hypertension, orthostatic hypertension and any other physiological variation in heart rate.

The non-invasive recording provides a quantitative evaluation of sympathovagal interaction modeling the cardiovascular function. Whether this methodology can be used with practical implementation pathological condition of paramount importance such as arterial HT, orthostatic hypotension toxemia of pregnancy for which the correlation between the aggravating and reliving neural factor if any is still under novel scrutiny. 
In consort with previous research, the examination in first year medical students is stressful enough to affect the performance adversely. Since stress around examinations is strongly predicting the academic achievement, students should be exposed to stress management techniques to help prevent the known high consequences.

Continued follow up of this study can provide information regarding changing response to stress and can help medical teaches understand more about stress among their students and guide them to improve in academic context which is important for student achievement.

\section{REFRENCES:}

1. Radcliffe $\mathrm{C}$, Lester $\mathrm{H}$. Perceived stress during undergraduate medical training a qualitative study. Medical Education. 2003; 37: 32-8.

2. Jenny F. Levels and sources of stress in medical students. British Medical Journal. 1986; 292: 1177-80.

3. Saipanish R. Stress among medical students in a Thai medical school. Med Teach 2003; 25(5): 502-6.

4. Wolf TM. Stress, coping and health: enhancing well-being during medical school. Medical Education 1994; 28: 8-17.

5. Kelly JA, Bradlyn AS, Dubbert PM, St Lawrence JS. Stress management training in medical school. Journal of Medical Education. 1982; 57(2): 91-9.

6. Rospenda KM, Halpert J, Richman JA. Effects of social support on medical students performance. Acad Med 1994; 69: 496-9.

7. Spiegel DA, Smolen RC, Jonas CK. An examination of the relationships among interpersonal stress, morale and academic performance in male and female medical students. Soc Sci Med 1986; 23(11): 1157-61.

8. Vaz RF, Mbajiorgu EF, Acuda SW. A preliminary study of stress levels among first year medical students at the University of Zimbabwe. Cent Afr. J. Med. 1998; 44(9): 214-9.

9. Vitaliano PP, Russo J, Carr JE, Heerwagen JH. Medical school pressures and their relationship to anxiety. K Nerv Dis 1984; 172(12): 730-6.

10. Sherina MS, Rampal L, Kaneson N. Psychological stress among undergraduate medical students. Med J Malaysia 2004; 59(2): 207-11.

11. Qureshi F. Effect of examination stress on blood cell parameters of students in a Pakistani Medical College. J Aub Med Coll. 2002; 14(1): 20-2.

12. Pike JL, Smith TL, Haugher RL, NIcassio PM, Patterson TL, McClintick J et al. Chronic life stress alters sympathetic, neuroendocrine, and immune responsivity to an acute psychological stressor in humans. Psychosom Med 1997; 59(4): 447-57.

13. Marshall GD, Agarwal SK, Lloyd C, Cohen L, Hinninger EM, Morris GJ. Cytokine dysregulation associated with exam stress in healthy medical students. Brain Behav. Immun. 1998; 12(4); 297-307.

14. Spielberger CD. Manual or the state trait anxiety inventory (Self-evaluation questionnaire Palo Alto, California, Consulting Psychologists Press 1970.

15. Ewing DJ, Clarke BF. Diagnosis and management of diabetic autonomic neuropathy. Br Med J 1982; 285: 916-20. 


\section{ORIGINAL ARTICLE}

16. Bohnen N, Houx P, Nicolson N, Jolles J. Cortisol reactivity and cognitive performance in a continuous mental task paradigm. Bio Psychol 1990; 31(2): 107-16.

\section{AUTHORS:}

1. Mahima Sharma

2. Mohit Sharma

3. K.C. Mathur

4. K.C. Oiha

5. Binawara

6. D.K. Deora

\section{PARTICULARS OF CONTRIBUTORS:}

1. Senior Demonstrator, Department of Physiology, Government Dental College, Jaipur, (Rajasthan).

2. Resident, Deptartment of C.T.V.S, S.M.S. Medical college, Jaipur (Rajasthan).

3. Professor Department of Physiology, S.P. Medical College, Bikaner (Rajasthan).

4. Professor and Head, Department of Physiology, S.P. Medical College, Bikaner (Rajasthan).
5. Associate Professor, Department of Physiology, S.P. Medical College, Bikaner (Rajasthan).

6. Assistant Professor, Department of Physiology, S.P. Medical College, Bikaner (Rajasthan).

\section{NAME ADDRESS EMAIL ID OF THE} CORRESPONDING AUTHOR:

Dr. Mahima Sharma,

E-1/383, Chitrakoot,

Vaishali Nagar,

Jaipur (Rajasthan) - 302021

E-mail: aries.mohit@gmail.com

Date of Submission: 26/01/2014.

Date of Peer Review: 27/01/2014.

Date of Acceptance: 04/02/2014.

Date of Publishing: 13/02/2014. 